\title{
Adaptive control of ventilation using electrical stimulation in a biomechanical model
}

\author{
Brian K Hillen ${ }^{1 *}$, James J Abbas ${ }^{2}$, Adeline Zbrzeski ${ }^{3}$, Sylvie Renaud ${ }^{3}$, Ranu Jung ${ }^{1}$ \\ From 24th Annual Computational Neuroscience Meeting: CNS*2015 \\ Prague, Czech Republic. 18-23 July 2015
}

Cervical spinal cord injury (SCI) causes loss or impairment of control of respiratory muscles. Life-sustaining ventilation can be provided by mechanical ventilators (which have numerous side effects) or open-loop electrical stimulation respiratory pacing systems [1]. The use of adaptive control strategies in respiratory pacing systems can simplify initial setup procedures and allow the system to adjust stimulation values to account for changes due to muscle fatigue and/or respiratory demand. We have implemented a neural network based adaptive controller [2] with a biomechanical model of human ventilator dynamics and diaphragm stimulation

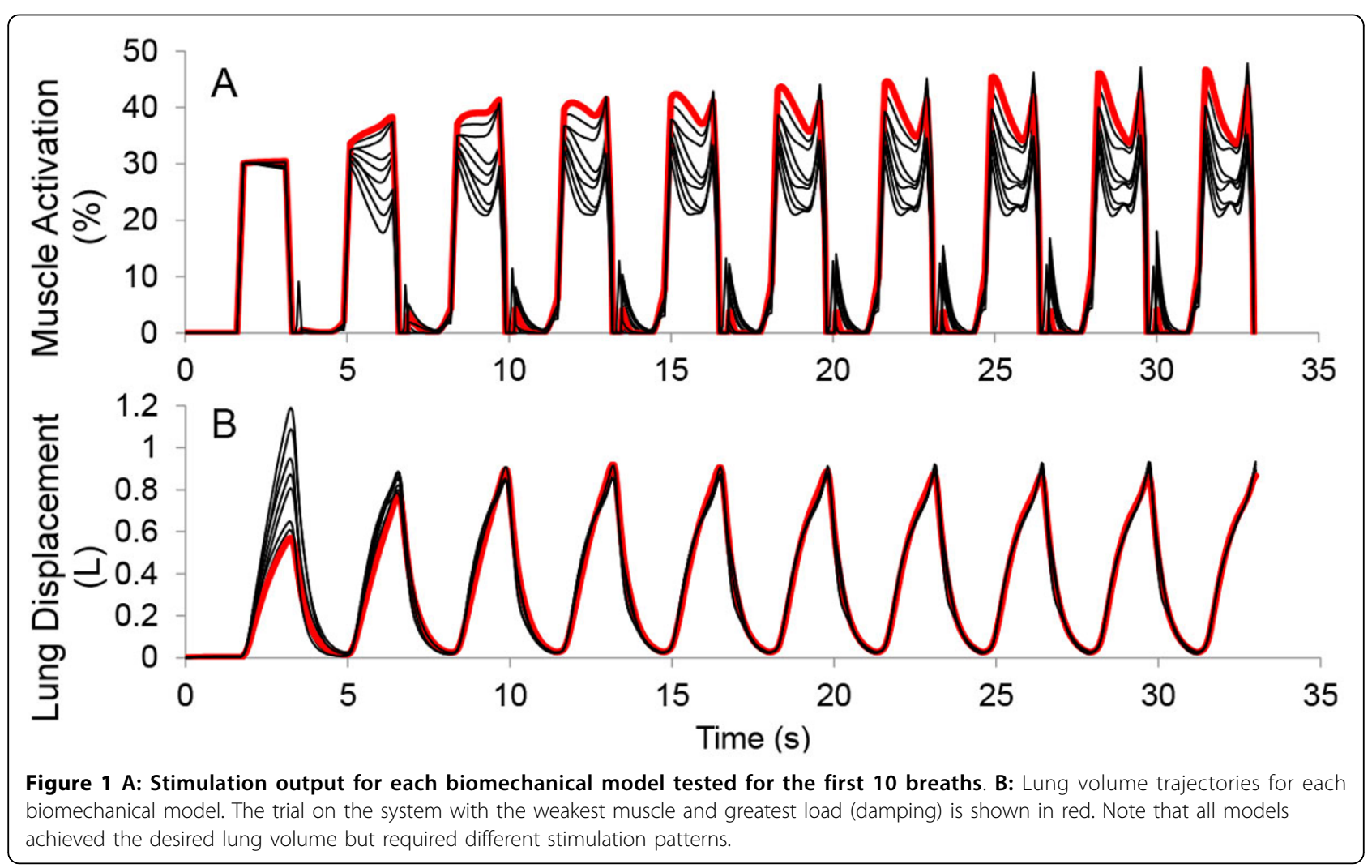

\footnotetext{
* Correspondence: Brian.Hillen@fiu.edu

'Department of Biomedical Engineering, Florida International University,

Miami, FL, 33174, USA

Full list of author information is available at the end of the article
} 
in Simulink/SimMechanics/ Matlab. The adaptive controller uses sensor information to automatically determine a stimulation pattern that will produce a prespecified desired lung volume trajectory. The controller uses a two-stage pattern generator/pattern shaper (PG/ PS) structure which has successfully controlled leg movements in human subjects [3] and rats [4] using neuromuscular electrical stimulation. The biomechanical model incorporates a physiologically realistic Hill-type muscle model and a damped spring with non-linear compliance using published parameters for muscle geometry [5]. The parameters of the biomechanical model (muscle mass and lung damping) were varied $+/-20 \%$ to simulate variation across a population to yield 9 sets of parameters. The quality of control and rate of adaptation achieved by the PG/PS controller were quantified by assessing the tracking error (difference between the actual and desired volume patterns) and the number of cycles needed to reach 5\% error. Controller parameters were initialized to provide a nominal degree of ventilation during initial breaths. For each set of biomechanical parameters, the controller adapted stimulation values to achieve the same desired volume trajectory without any modification of initial controller values (Figure 1) and to achieve less than $5 \%$ error in $1-10$ (mean $5.4 \pm 2.6$ ) cycles. This adaptive strategy will be investigated further in simulation as well as hardware implementations for testing in animal models.

\section{Acknowledgements}

This work was supported by NIH R01-NS086088 and ANR-13-NEUC-0001-01.

\section{Authors' details}

${ }^{1}$ Department of Biomedical Engineering, Florida International University, Miami, FL, 33174, USA. ${ }^{2}$ School of Biological and Health Systems Engineering, Arizona State University, Tempe, AZ, 85287, USA. ${ }^{3}$ IMS Laboratory, CNRS UMR 5218,Institut Polytechnique de Bordeaux, Talence, 33405, France.

Published: 18 December 2015

\section{References}

1. Hillen B, Jung R: Peripheral Nerve Interface Applications, Respiratory Pacing. In Encyclopedia of Computational Neuroscience. Berlin Heidelberg: Springer-Verlag;Jaeger D, Jung R 2013:.

2. Stites EC, Abbas JJ: Sensitivity and versatility of an adaptive system for controlling cyclic movements using functional neuromuscular stimulation. IEEE Trans Biomed Eng 2000, 47:1287-1292.

3. Riess J, Abbas JJ: Adaptive neural network control of cyclic movements using functional neuromuscular stimulation. IEEE Trans Rehabil Eng 2000, 8:42-52.

4. Fairchild MD, Kim SJ, larkov A, Abbas JJ, Jung R: Repetetive hindlimb movement using intermittent adaptive neuromuscular electrical stimulation in an incomplete spinal cord injury rodent model. Exp Neurol 2010, 223:623-633.

5. Hillen $B$, Jung R: Computational model of human ventilation for electrical stimulation following cervical spinal cord injury. BMC Neuroscience 2014, 15:P133.
doi:10.1186/1471-2202-16-S1-P111

Cite this article as: Hillen et al:: Adaptive control of ventilation using electrical stimulation in a biomechanical model. BMC Neuroscience 2015 16(Suppl 1):P111.

\section{Submit your next manuscript to BioMed Central and take full advantage of:}

- Convenient online submission

- Thorough peer review

- No space constraints or color figure charges

- Immediate publication on acceptance

- Inclusion in PubMed, CAS, Scopus and Google Scholar

- Research which is freely available for redistribution

Submit your manuscript at www.biomedcentral.com/submit
C Biomed Central 